\title{
Open
}

\section{Arginine depletion increases susceptibility to serious infections in preterm newborns}

\author{
Shiraz Badurdeen ${ }^{1}$, Musa Mulongo ${ }^{2}$ and James A. Berkley ${ }^{2,3}$
}

Preterm newborns are highly susceptible to bacterial infections. This susceptibility is regarded as being due to immaturity of multiple pathways of the immune system. However, it is unclear whether a mechanism that unifies these different, suppressed pathways exists. Here, we argue that the immune vulnerability of the preterm neonate is critically related to arginine depletion. Arginine, a "conditionally essential" amino acid, is depleted in acute catabolic states, including sepsis. Its metabolism is highly compartmentalized and regulated, including by arginase-mediated hydrolysis. Recent data suggest that arginase II-mediated arginine depletion is essential for the innate immune suppression that occurs in newborn models of bacterial challenge, impairing pathways critical for the immune response. Evidence that arginine depletion mediates protection from immune activation during first gut colonization suggests a regulatory role in controlling gut-derived pathogens. Clinical studies show that plasma arginine is depleted during sepsis. In keeping with animal studies, small clinical trials of L-arginine supplementation have shown benefit in reducing necrotizing enterocolitis in premature neonates. We propose a novel, broader hypothesis that arginine depletion during bacterial challenge is a key factor limiting the neonate's ability to mount an adequate immune response, contributing to the increased susceptibility to infections, particularly with respect to gut-derived sepsis.

\section{THE PRETERM IMMUNE SYSTEM}

The immune system of the preterm neonate faces a unique challenge. Although still very early in the process of development and maturation, it must quickly adapt to respond appropriately to a variety of antigenic challenges following early delivery of the fetus. While in the protected, and usually sterile, intrauterine environment, evolutionary regulation against excessive immune activation is advantageous (1). A reduced inflammatory response is likely also to be protective during the large antigenic exposure from microbes encountered during delivery, subsequent environmental exposure, and gut colonization. However, the preterm neonate must thereafter be capable of mounting a selective and appropriate protective immune response to pathogenic challenges; indeed they face an unusually high exposure from such pathogens while being nursed in hospital environments and exposed to invasive medical procedures.

In order to achieve this environmentally and temporally dependent adjustment in immune responsiveness, the preterm neonate has at its disposal a repertoire of maturing immune components. Foremost is the role played by the innate-immune component, which unlike the adaptive immunity does not require previous antigenic exposure for activation and can effect rapid pathogen clearance (2). The preterm neonate, in most cases, successfully addresses the immunological challenges described above through a variety of appropriate homeostatic cellular and molecular mechanisms (1). Particularly prominent in response to antigenic stimulation is the production of regulatory cytokines by innate immune cells, relatively low production of classical proinflammatory cytokines including type 1 interferons (IFNs), interleukin (IL)-12 and T helper 1 (Th1)-type responses, and, in contrast to fullterm neonates, weak T helper 17 (Th17)-supporting cytokines (2). This results in a homeostatic set-point that is regulated toward hyporesponsiveness to antigenic challenge, one that is advantageous to the intrauterine environment and immediate postdelivery antigenic exposure. With increasing age, this homeostatic regulation shifts toward favoring increasingly proinflammatory responses: proinflammatory cytokine production increases, and innate cells show enhanced chemotaxis, migration, opsonization, phagocytic ability, intracellular bactericidal activity, and oxidative responses (3). The progression from $\mathrm{T}$ helper 2 (Th2) cell and regulatory $\mathrm{T}$ cell populations toward proinflammatory Th1-type responses results in greater cytotoxic adaptive immune capability (1). In addition, preterm neonates receive less protective maternal antibody transfer than normally occurs in the third trimester of pregnancy, and the infant's own antibody response becomes fully mature in during later infancy (3). The time-scale of this immune maturation occurs over a period of weeks to months, and the interim period represents a period of immune vulnerability for the preterm neonate. This correlates with clinically apparent susceptibility to infection that diminishes with age (4).

Understanding the cellular and molecular mechanisms that regulate neonatal suppressed immune responses has been challenging. It is unclear, for example, how the suppressed 


\section{Arginine in preterm newborn immunity}

proinflammatory state is initiated and subsequently regulated in the neonatal period. An important area of uncertainty is whether a mechanism that unifies the suppression of the different cellular and systemic proinflammatory pathways exists. Clearly, a better understanding in this area is critical for developing future therapeutic strategies aimed at adjusting the homeostatic set point so that the immune system can better respond to pathogens. In this review, we argue for a key role for compartmentalized arginine metabolism in regulating disparate pathways of the immune system critical for host defense in preterm neonates. Taking into consideration mechanistic and clinical evidence, we propose a novel, broad hypothesis-compartmentalized arginine depletion during bacterial challenge is a key factor limiting the preterm newborn's ability to mount an adequate innate-immune and Th1 response, contributing to the increased susceptibility particularly to gut-derived sepsis. We suggest that interventions aimed at limiting arginine depletion, timed after the initial phase of gut colonization by commensals, would be beneficial in adjusting the homeostatic immune set point in preterm neonates toward boosting the protective immune response.

\section{ARGININE AVAILABILITY IS AN IMPORTANT MECHANISM OF IMMUNE REGULATION}

L-arginine is considered a "conditionally essential" aminoacid. Protein breakdown is the predominant source, while a smaller proportion is obtained through the diet, including through metabolic conversion of dietary glutamate (via citrulline) in the kidneys (5). Kinetic studies in adults show tight compartmentalized metabolism that dramatically restricts the use of the plasma arginine pool, allowing fine regulation at cellular and subcellular levels by local metabolic processes (6). Plasma levels of arginine may therefore be dramatically different to cellular and subcellular levels, particularly in the early stages of catabolism and/or in the context of infective challenges, but may be taken up by local pools and subsequently reflect an arginine-depleted state during consumption.

This compartmentalization enables competitive metabolism by two major enzymatic pathways: arginase and NO synthase (NOS). Arginase I is expressed in erythrocytes, hepatocytes, and, depending on the species, subtypes of myeloid cells, while arginase II is a mitochondrial protein expressed prominently in the kidney, small intestine and lactating mammary gland (7). Arginase converts arginine to ornithine, which along with its metabolites are substrates for cell proliferation, collagen synthesis, and tissue regeneration. In doing so, arginine substrate is effectively diverted away from the second pathway in which nitric oxide synthase utilizes arginine to generate nitric oxide and reactive nitrogen species (8). NO synthesis from L-arginine is a well-established pathway important both in bacteria and in multicellular organisms; in fact, nearly all eukaryotes are capable of generating NO from nitric oxide synthases (9). The dichotomized arginine regulation between arginase and NOS is found in fish, and is likely to be an old evolutionary program (10). In mice, inducible NOS (iNOS) induction reflects classical activation of macrophages, central to cellular immunity

\section{Integrated Mechanism Review}

against intracellular and extracellular bacteria (11). Arginine availability plays a key role in the initiation of intracellular signaling pathways that trigger the lipopolysaccharide-induced inflammatory responses in murine macrophages (12). Mieulet et al. (13) showed that arginine substrate limitation critically affects toll-like receptor-4 (TLR-4)-mediated intracellular signaling. In starved mice with plasma arginine depletion, they showed that arginine supplementation restored the activation of mitogen-activated protein kinases and tumor necrosis factor (TNF)- $\alpha$ production in response to lipopolysaccharide, a major pathway for generating a proinflammatory response. Augmenting TLR-4 signaling has clearly been demonstrated to be protective in animal models of neonatal sepsis through enhancing neutrophil numbers and oxidative burst capacity $(14,15)$. Arginine substrate limitation for NOS is mediated in mice by arginase I, predominantly released by myeloid suppressor cells that are capable of dramatically depleting arginine from the microenvironment (7). In human adults, arginase I is expressed by polymorphonuclear granulocytes (16), and is released upon activation or cell death leading to arginine depletion in the microenvironment (17). Arginine depletion has profound effects on T-cell function, causing downregulation of the T cell receptor $z$-chain (a critical signaling element of the T cell receptor), impaired cytokine secretion and diminished T-cell proliferation that is reversible upon L-arginine supplementation $(7,17,18)$. Arginase 1 released by hemolysing red cells has been shown in a transfusion model to be a further source of arginine depletion resulting in impaired T-cell proliferation (19). More recent studies demonstrate that the regulatory role of arginine availability extends to human natural killer (NK) cells, where arginine depletion limits proliferation, expression and signaling of activating receptors, cytotoxicity, and IFN- $\gamma$ secretion $(20,21)$. Arginine depletion and consequent restriction of $\mathrm{NO}$ synthesis may have important effects on immune-signaling, including IL-12-dependent NK cell activation, Th1 differentiation, and Treg induction (22-24). In vitro, constitutive arginase I expression in polymorphonuclear granulocytes does not appear to be controlled by pro- and anti-inflammatory cytokines (16). However, in states of disease, arginase I expression has been shown in the peripheral blood mononuclear cell fraction, and specifically from monocytes and low-density granulocytes $(25,26)$. In summary, through arginine depletion, arginase expressing cells exert a unique role, regulating at least four important biological processes: the generation of the antimicrobial mediator nitric oxide, activation of TLR-4-mediated proinflammatory responses, and maturation of NK cell and T-cell function.

What conditions result in enhanced arginase-mediated arginine depletion and do these exist in newborns? A landmark paper recently showed that neonates possess a uniquely enriched population of immunosuppressive $\mathrm{CD}^{2} 1^{+}$cells that produce the enzyme arginase II, essential for susceptibility to infection (27). In their paper, Elahi et al. first showed that transferring adult splenocytes (containing immune cells) to neonatal mice failed to protect against Listeria monocytogenes infection, and Th1-polarizing TNF- $\alpha$ production was 


\section{Integrated Mechanism Review}

diminished. Conversely, transfer of neonatal splenocytes to $L$. monocytogenes infected adult mice restored TNF- $\alpha$ production. Similar results were seen in human cord blood, suggesting that neonatal infection susceptibility is related to active immune suppression by the neonatal environment. This suppression was shown to be mediated by arginine depletion through arginase II production by physiologically enriched $\mathrm{CD}_{71^{+}}$erythroblasts, as inhibition of arginase II or supplementation by L-arginine overcame the immune-suppressive effects of the neonatal environment. Indeed, the susceptibility to L. monocytogenes and Escherichia coli diminished with natural decline in $\mathrm{CD} 1^{+}$cells during postnatal development, as well as with antibody-mediated depletion of these cells. These results identify a new mechanism of arginase-mediated arginine depletion unique to newborns that is an essential component of immune susceptibility to infection. Furthermore, cord blood mononuclear cells express higher levels of arginase I than adult mononuclear cells (28). Addition of exogenous L-arginine to cord blood that contained lower levels of plasma arginine enhanced neonatal lymphocyte proliferation through an IL-2-independent pathway, but had no effects on adult lymphocyte proliferation (28).

There are arguably similarities in the importance, both in human newborns and in lower organisms, of innate immunity for host-defense, and the use of arginase-mediated-arginine metabolism to regulate this defense. A further example of such shared immune mechanisms is trained innate-immunity, a mechanism for innate-immune memory with emerging importance in human newborns (29). Pathways well characterized in rodents that regulate arginase expression may therefore be particularly relevant in human neonates. Specifically, it has been shown in rodents that Th1/Th2 polarization determines arginase I and iNOS expression, and subsequently arginine availability. Th2 cytokines increase cellular uptake of arginine via the cationic amino acid (CAT) transporter and induce arginase I activity via STAT6 (30). This couples extracellular arginine depletion with intracellular enzymatic diversion away from NO synthesis, leading to the alternative activation phenotype of macrophages (31). Conversely, Th1 cytokines (TNF- $\alpha$, IFN- $\gamma$ ) and endotoxin couple enhanced L-arginine uptake with increased iNOS-mediated NO production and classical macrophage activation via the transcription factors NF- $\mathrm{KB}$ and STAT1 $(7,32)$. The Th1/Th2 balance against Th1 polarizing responses in preterm newborns may similarly drive arginase I and perhaps arginase II activation, arginine depletion, and diversion away from a proinflammatory state (Figure 1). There is little data on the relationship between arginine homeostasis and Th17-type adaptive immunity; however, a study in patients with sickle-cell disease showed a correlation between arginase I levels and Th17 inducing transforming growth factor- $\beta$, but no correlation with IL-17 or IL-23 (33). Taken together, these lines of evidence delineate the mechanisms by which, during a pathogenic challenge, the preterm newborn is programmed toward developing an arginasemediated arginine depleted state, and is thereby less primed to generate a proinflammatory immune response. This situation

\section{Badurdeen et al.}

may be compounded by the use of arginase by certain microorganisms. Arginine depletion is an emerging mechanism of virulence that enables host immune evasion, and has been demonstrated in Mycobacterium, Leishmania, Trypanosoma, Helicobacter, Schistosoma, and Salmonella spp. (34). In conditions of increased extracellular arginine, the neonatal pathogens Streptococcus sp., E. coli, and Klebsiella sp. increase production of ornithine, suggestive of arginase and arginine deiminase pathway activity, effectively limiting availability for NO synthesis (35). A similar strategy for immune evasion might explain the findings of increased arginine transport and decreased arginine biosynthesis found in the microbiome of patients with the adult gut inflammatory conditions ulcerative colitis and Crohn's disease (36).

\section{DOES AN ARGININE DEFICIENCY STATE CONTRIBUTE TO CLINICAL SEPSIS?}

There is substantial evidence from adult studies showing depletion of plasma arginine in patients with sepsis compared to nonseptic controls, as summarized in a meta-analysis by Davis et al. (37). A recent study of pediatric sepsis measured daily levels of arginine, asymmetric dimethylarginine (an endogenous NOS inhibitor), ornithine, and citrulline (38). The results showed significantly lowered levels of plasma arginine in septic patients compared with febrile, nonseptic, and healthy controls. Interestingly, septic patients had decreased ratio of arginine:ornithine suggesting increased arginase activity, but no difference in citrulline:arginine ratio, which is an indirect measure of NOS synthase activity. Furthermore, there was a nonsignificant trend toward lower arginine: asymmetric dimethylarginine ratio in septic patients with slow recovery, suggesting lower arginine bioavailability for NOS, when compared to patients with rapid recovery. Finally, there appeared to be a stepwise reduction in the above markers from healthy controls to febrile nonseptic patients to septic patients, suggesting a role for arginine-NOS substrate limitation even in less severe (or early stages) of infection. Consistent with these findings, studies in premature newborns with necrotizing enterocolitis (NEC) have shown significantly lower levels of plasma arginine and citrulline, suggesting arginine substrate limitation for $\operatorname{NOS}(39,40)$. A useful study by Becker et al. (41) serially measured multiple amino acids in preterm neonates during the first $21 \mathrm{~d}$ of life. The results showed lower levels of arginine (and glutamine) upto a week prior to the diagnosis of NEC when compared to controls who did not develop NEC, despite similar levels of amino acid intake, suggesting involvement in the pathogenic processes leading to the disease. Furthermore, there is increasing evidence of an association between red cell transfusion and NEC, possibly related to release of arginase I from erythrocytes during storage and subsequent systemic arginine hydrolysis upon transfusion $(19,42)$. Preterm formula increases the risk of NEC when compared to human preterm milk, and while containing similar quantities of total L-arginine, preterm formula contains $\sim 20$ times less free L-arginine (and similarly low levels of total free amino acids) (43). Free amino acids are more readily absorbed than 


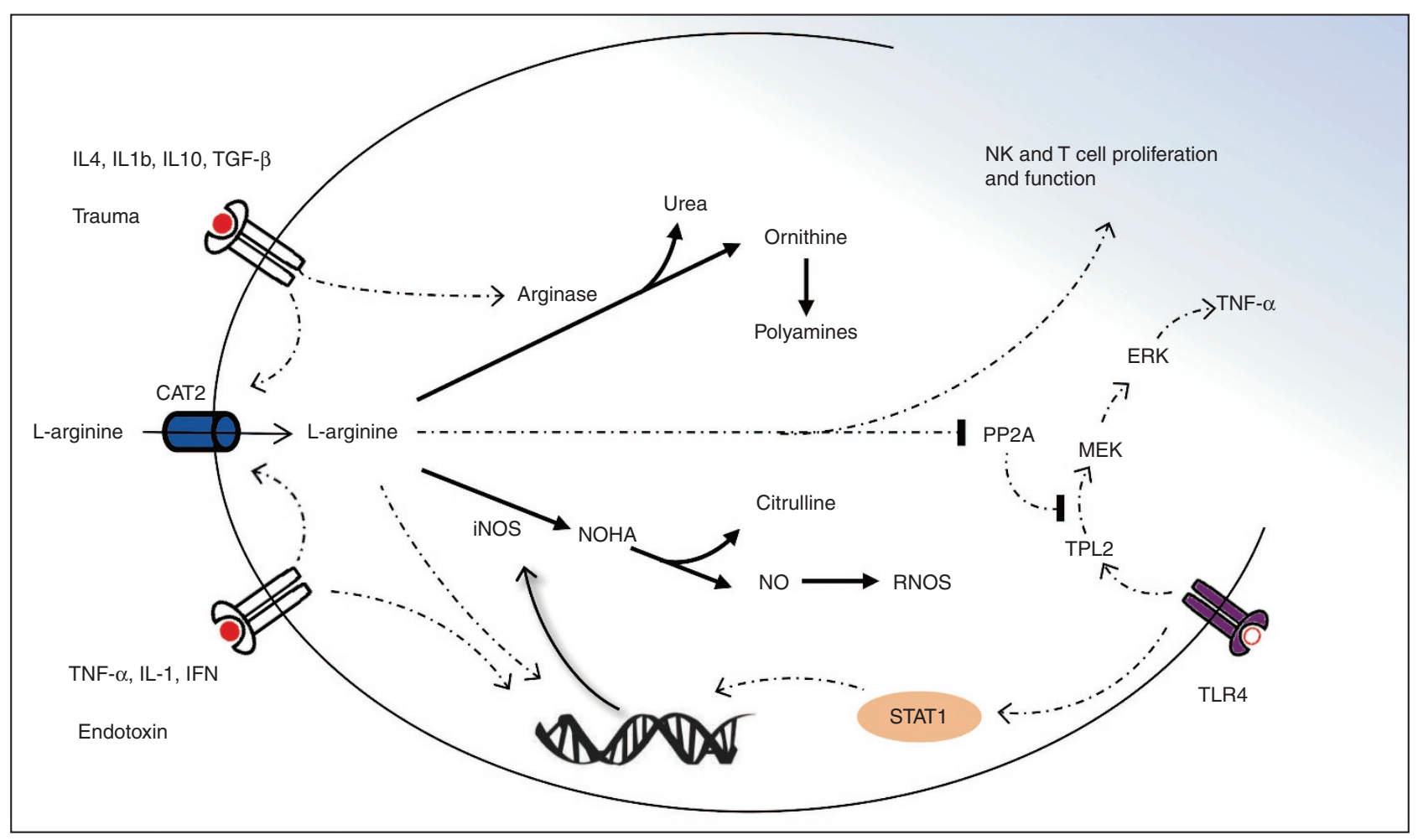

Figure 1. Schematic representation of pathways regulating arginine metabolism and downstream signaling. L-arginine uptake via the cationic aminoacid transporter is stimulated by pro- and anti-inflammatory cytokines. (a) Th2 regulatory cytokine environment upregulates arginase, driving ornithine synthesis and competitively depleting arginine substrate for iNOS. iNOS may be induced by proinflammatory cytokines and endotoxin through NF- $\kappa B$ and STAT1 signaling. Translation of iNOS mRNA is further enhanced by increased L-arginine availability (79). Increased iNOS activity results in the production of NG-hydroxy-L-arginine (NOHA), nitric oxide (NO), and reactive nitric oxygen species. There is evidence of crossinhibition between metabolites of these two pathways: inducible NO synthase (iNOS) is inhibited by polyamines produced from ornithine metabolism, and arginase is inhibited by NOHA $(8,80)$. Increased L-arginine availability limits PP2A-mediated dephosphorylation and inactivation of TPL2, promoting the subsequent activation of ERK1/2 and the production of TNF- $\alpha$ in response to lipopolysaccharide. Increased L-arginine availability in the cellular environment upregulates NK and T cell receptors, promotes activation and proinflammatory cytokine production. ERK, extracellular signal-regulated kinase; PP2A, protein phosphatase $2 \mathrm{~A}$; TPL2, tumor-promoting locus 2 (for the sake of clarity, not all steps in the signaling pathways are shown. See text for further references).

protein-derived amino acids contributing to the initial change in plasma free amino acids following a feed; however their full biological significance remains unclear (44).

Several studies of arginine supplementation have been carried out in adults for the prevention or treatment of sepsis. Arginase I upregulation by myeloid cells in conditions of physical stress such as surgery and trauma is thought to lead to an arginine deficiency syndrome contributing to susceptibility to infection (45). Dietary arginine supplementation, alone or in combination with other immunoactive nutrients including o-3 fatty acids and nucleotides, has been extensively trialed in high-risk and elective surgical patients, with significant reductions in postoperative infections (46). Based on these studies, the European Society of Parenteral and Enteral Nutrition recommends its use in major surgery and severe trauma (47). In the adult critical care setting, however, the role of arginine supplementation in sepsis continues to be debated (48). This is largely because the studies have been carried out in heterogeneous populations with varying doses of arginine, often combined with other immunonutrients, delivered enterally, intravenously, or combined (49). One study evaluating an arginine-enriched formula in a focused population of septic intensive care patients showed benefit for nosocomial infections and mortality particularly in patients with lesssevere illness, suggesting that efficacy may be lost in patients with septic shock (50). Bertolini et al. (51) compared a low arginine-containing enteral formula to total parenteral nutrition in a poorly stratified, unblinded study, with most patients having pneumonia on entry into the study. The study was discontinued prior to completion due to increased mortality in the enteral immunonutrition group. Animal models have shown similar conflicting results, with harmful effects seen in two studies using intravenous and/or high-dose L-arginine supplementation during models of septic shock (52) or prolonged sepsis (53). It may be possible that L-arginine supplementation during severe sepsis/septic shock may compound hemodynamic instability by increasing levels of NO-mediated vasodilatation. Furthermore, enteral delivery of any formula in patients with shock is generally contraindicated due to the risk of gut ischemia (54). However, the standard of care currently for preterm neonates in the first few days of life while feeds are being established, and indeed during episodes when feeding is contraindicated including NEC and sepsis, is to provide total parenteral nutrition, which contains significant quantities of arginine (and other amino acids). Current recommendations are for amino acids to be commenced on the first postnatal 


\section{Integrated Mechanism Review}

day at $1.5 \mathrm{~g} / \mathrm{kg} /$ day, increasing up to $4 \mathrm{~g} / \mathrm{kg} /$ day (55). The arginine component of this in commonly used preparations is between $125-340 \mathrm{mg} / \mathrm{kg} /$ day, and appears to be safe in practice (56) (PRIMENE 10\% -BAXTER (Baxter Healthcare Pty, Old Toongabbie, Australia)). A study in acutely unwell neonates who were receiving parenteral nutrition demonstrated that plasma arginine levels were upto twofold higher than full-term controls (57), and may indicate that supplementation during sepsis is likely to adequately increase both the plasma and compartmentalized L-arginine pools.

Several animal studies supplementing arginine prior to the onset of sepsis and/or predominantly using enteral or lowdose intravenous supplementation, show favorable effects on markers of immunological function $(58,59)$, bacterial invasion (60), gut bacterial translocation $(61,62)$, and physiological parameters (63). Notably, the differential effects on mucosal immune parameters and macrophage phagocytic activity of enteral arginine supplementation before caecal ligation and puncture vs. intravenous arginine administration after caecal ligation and puncture, were shown in a model of rat sepsis $(64,65)$. Newborn animal models of arginine supplementation have shown favorable effects on intestine oxidative stress levels and mucosal growth, as well as Cryptosporidium parvum infection in mice (66-68). Importantly, the addition of arginine to porcine intestinal cells dose-dependently inhibited LPSinduced TLR4/NF-KB signaling and cell death, a key pathway in the pathogenesis of necrotizing enterocolitis $(69,70)$. In an important study, Yazji et al. (71) showed in a mouse model that endothelial TLR4 activation is required for NEC, via inhibition of endothelial NO production and impaired intestinal perfusion. Restoration of NO signaling reversed this effect. In keeping with these findings, two small trials of L-arginine

\section{Badurdeen et al.}

supplementation in human preterm newborns have shown efficacy in reducing the incidence of NEC. In a double-blind, placebo controlled trial, Amin et al. (72) randomized 152 neonates with gestational age $<32 \mathrm{wk}$ to either supplemental L-arginine (1.5 mmol/kg per day) or placebo with oral feeds/ parenteral nutrition during the first $28 \mathrm{~d}$ of life. They reported a $76 \%$ reduction in the incidence of Stage I-III NEC in the L-arginine group that corresponded with twofold higher levels of plasma L-arginine. Interestingly, lower levels of plasma arginine were detected at the time of diagnosis of NEC for patients in both groups. Polycarpou et al. (73) in a recent double-blind, placebo controlled trial randomized 83 neonates with gestational age $<34 \mathrm{wk}$ to receive enteral L-arginine supplementation $(1.5 \mathrm{mmol} / \mathrm{kg}$ per day) or placebo between the $3 \mathrm{rd}$ and 28 th day of life. They found statistically significant reductions in stage III NEC and NEC-related mortality in the L-arginine group, with a trend toward lower incidences of all stages of NEC in this group. Neither study reported adverse events related to L-arginine supplementation.

\section{HYPOTHESIS: ARGININE IS A KEY REGULATOR OF MUCOSAL IMMUNITY AND ITS DEPLETION IN PRETERM NEWBORNS INCREASES SUSCEPTIBILITYTO GUT-DERIVED PATHOGENS}

In addition to its role in systemic immunity described above, several lines of evidence point toward a prominent role for arginine in gut-mucosal immunity. Elahi et al. (27), in addition to showing that arginase II from CD71 ${ }^{+}$erythroblasts is essential for neonatal innate-immune suppression, demonstrated that this mechanism is critical to prevent inappropriate immune activation after birth at the time of first gut colonization. It appears that the need to reduce inflammation

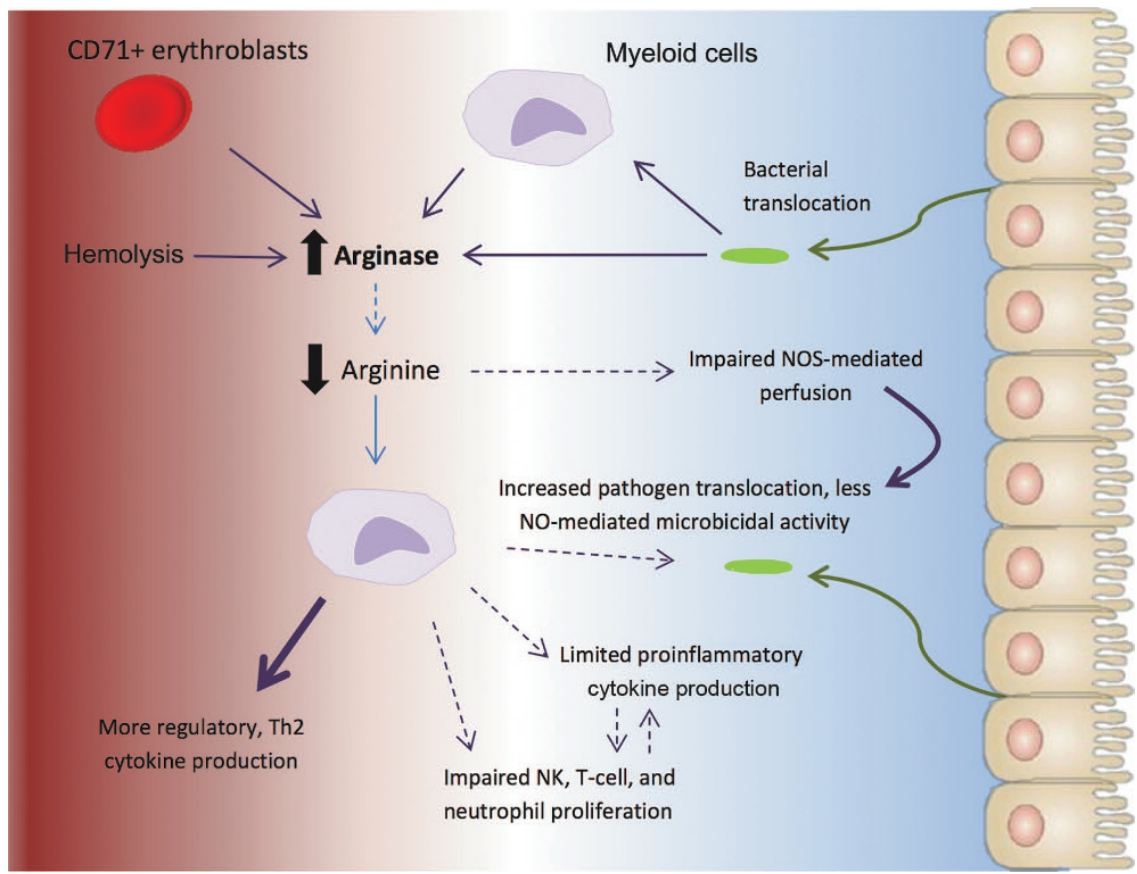

Figure 2. Conditions contributing to arginase-mediated arginine depletion in the preterm neonate and subsequent mechanisms of susceptibility to gut-derived pathogens. 


\section{Arginine in preterm newborn immunity}

in response to early-life commensal colonization comes at the price of increased susceptibility to infection. With increasing postnatal age, however, there is a temporal decline in $\mathrm{CD}_{71} 1^{+}$cells, reflecting increasing proinflammatory capacity (27). It is possible that this temporal maturation, similar to the maturation of other arms of the immune system in preterm newborns, is delayed leading to a prolonged period of susceptibility to infection. Indeed, the level of plasma $\mathrm{L}$-arginine is low in preterm/lower birthweight babies and increases with postnatal age $(74,75)$. It is likely that arginine metabolism in the preterm newborn continues to play an important role in regulating gut and systemic immunity beyond the first few hours-days of life. Indeed, the role of gut-bacterial translocation in newborn sepsis has long been suspected, and recent studies have provided new evidence suggesting this as an under-appreciated source of systemic infection $(76,77)$. The mechanistic links between microbiome, mucosal immune response, and systemic infection in neonates was recently demonstrated in neonatal mice, and highlighted the importance of microbiome-induced TLR-4 and IL-17 signaling for neutrophil development and resistance to sepsis (15). In keeping with the above, arginine appears to act locally through NO-dependent and NO-independent mechanisms to affect gut permeability, limit bacterial translocation and kill translocated organisms in adult mouse models $(60,62,78)$. Fascinatingly, Chau et al. (61) showed in mice that malaria-associated L-arginine deficiency induces mast cell-associated disruption to intestinal barrier defenses against nontyphoidal Salmonella bacteremia. These lines of evidence form the basis of a hypothesis (Figure 2): arginine plays a key role at the interface of the local and systemic immune responses to gut-derived sepsis, particularly important in the preterm neonate that is more susceptible to developing arginine deficiency during pathogenic challenge. We propose that interventions aimed at limiting arginine depletion would be beneficial in boosting the protective immune response.

The hypothesis presented here invites further work to firmly establish a central role for arginine homeostasis in neonatal infection. While systemic arginine depletion has been shown in neonatal NEC, this is yet to be demonstrated in other examples of neonatal sepsis. Does the compartmentalized metabolism model hold in neonates, and is arginine homeostasis (particularly via arginase) regulated by the Th1/Th2/Th17 environment? How does this change with developmental age? Importantly, does arginine deficiency/lower arginine bioavailability translate to an increased risk of subsequent infections both in preterm and full-term neonates? Conversely, are neonates that have more favorable arginine bioavailability relatively protected, and if so, can the immunological mechanisms that mediate this protection be identified? Finally, translational clinical trials are needed to evaluate the strategy of therapeutically enhancing L-arginine bioavailability, such as L-arginine supplementation, as a means of boosting neonatal immunity and preventing neonatal infections.

\section{Integrated Mechanism Review}

\section{ACKNOWLEDGMENT}

The authors sincerely thank Pascale Kropf for her helpful comments on the manuscript.

\section{STATEMENT OF FINANCIAL SUPPORT}

S.B. is supported by a National Institute of Health Research (UK) Academic Clinical Fellowship.

Disclosure: The authors declare that they have no financial ties to any products discussed in this review and have no conflicts of interest.

\section{REFERENCES}

1. Ghazal P, Dickinson P, Smith CL. Early life response to infection. Curr Opin Infect Dis 2013;26:213-8.

2. Kollmann TR, Levy O, Montgomery RR, Goriely S. Innate immune function by Toll-like receptors: distinct responses in newborns and the elderly. Immunity 2012;37:771-83.

3. Ygberg S, Nilsson A. The developing immune system - from foetus to toddler. Acta Paediatr 2012;101:120-7.

4. Berkley JA, Lowe BS, Mwangi I, et al. Bacteremia among children admitted to a rural hospital in Kenya. N Engl J Med 2005;352:39-47.

5. Wu G, Morris SM Jr. Arginine metabolism: nitric oxide and beyond. Biochem J 1998;336 (Pt 1):1-17.

6. Mariotti F, Petzke KJ, Bonnet D, et al. Kinetics of the utilization of dietary arginine for nitric oxide and urea synthesis: insight into the arginine-nitric oxide metabolic system in humans. Am J Clin Nutr 2013;97:972-9.

7. Munder M. Arginase: an emerging key player in the mammalian immune system. Br J Pharmacol 2009;158:638-51.

8. Bronte V, Zanovello P. Regulation of immune responses by L-arginine metabolism. Nat Rev Immunol 2005;5:641-54.

9. Stuehr DJ. Mammalian nitric oxide synthases. Biochim Biophys Acta 1999;1411:217-30.

10. Joerink M, Forlenza M, Ribeiro CM, de Vries BJ, Savelkoul HF, Wiegertjes GF. Differential macrophage polarisation during parasitic infections in common carp (Cyprinus carpio L.). Fish Shellfish Immunol 2006;21:561-71.

11. Yeramian A, Martin L, Serrat N, et al. Arginine transport via cationic amino acid transporter 2 plays a critical regulatory role in classical or alternative activation of macrophages. J Immunol 2006;176:5918-24.

12. Pekarova M, Kubala L, Martiskova H, et al. The unique role of dietary $\mathrm{L}$-arginine in the acceleration of peritoneal macrophage sensitivity to bacterial endotoxin. Immunol Res 2013;56:73-84.

13. Mieulet V, Yan L, Choisy C, et al. TPL-2-mediated activation of MAPK downstream of TLR4 signaling is coupled to arginine availability. Sci Signal 2010;3:ra61

14. Wynn JL, Scumpia PO, Winfield RD, et al. Defective innate immunity predisposes murine neonates to poor sepsis outcome but is reversed by TLR agonists. Blood 2008;112:1750-8.

15. Deshmukh HS, Liu Y, Menkiti OR, et al. The microbiota regulates neutrophil homeostasis and host resistance to Escherichia coli K1 sepsis in neonatal mice. Nat Med 2014;20:524-30.

16. Munder M, Mollinedo F, Calafat J, et al. Arginase I is constitutively expressed in human granulocytes and participates in fungicidal activity. Blood 2005; 105:2549-56

17. Munder M, Schneider H, Luckner C, et al. Suppression of T-cell functions by human granulocyte arginase. Blood 2006;108:1627-34.

18. Kropf P, Baud D, Marshall SE, et al. Arginase activity mediates reversible $\mathrm{T}$ cell hyporesponsiveness in human pregnancy. Eur J Immunol 2007;37:935-45.

19. Bernard A, Kasten M, Meier C, et al. Red blood cell arginase suppresses Jurkat ( $\mathrm{T}$ cell) proliferation by depleting arginine. Surgery 2008:143:286-91.

20. Oberlies J, Watzl C, Giese T, et al. Regulation of NK cell function by human granulocyte arginase. J Immunol 2009;182:5259-67.

21. Lamas B, Vergnaud-Gauduchon J, Goncalves-Mendes N, et al. Altered functions of natural killer cells in response to L-Arginine availability. Cell Immunol 2012;280:182-90. 
22. Diefenbach A, Schindler H, Röllinghoff M, Yokoyama WM, Bogdan C. Requirement for type $2 \mathrm{NO}$ synthase for IL-12 signaling in innate immunity. Science 1999;284:951-5.

23. Niedbala W, Wei XQ, Campbell C, Thomson D, Komai-Koma M, Liew FY. Nitric oxide preferentially induces type $1 \mathrm{~T}$ cell differentiation by selectively up-regulating IL-12 receptor beta 2 expression via cGMP. Proc Natl Acad Sci USA 2002;99:16186-91.

24. Niedbala W, Cai B, Liu H, Pitman N, Chang L, Liew FY. Nitric oxide induces $\mathrm{CD} 4+\mathrm{CD} 25+$ Foxp3 regulatory $\mathrm{T}$ cells from CD4+CD25 T cells via p53, IL-2, and OX40. Proc Natl Acad Sci USA 2007;104:15478-83.

25. Rouzaut A, Subirá ML, de Miguel C, et al. Co-expression of inducible nitric oxide synthase and arginases in different human monocyte subsets. Apoptosis regulated by endogenous NO. Biochim Biophys Acta 1999;1451:319-33.

26. Takele Y, Abebe T, Weldegebreal T, et al. Arginase activity in the blood of patients with visceral leishmaniasis and HIV infection. PLoS Negl Trop Dis 2013; 7:e1977.

27. Elahi S, Ertelt JM, Kinder JM, et al. Immunosuppressive CD71+ erythroid cells compromise neonatal host defence against infection. Nature 2013;504:158-62.

28. Yu H-R, Kuo H-C, Chen C-C, et al. L-arginine modulates neonatal lymphocyte proliferation through IL-2 independent pathway. Immunology 2014;143:184-92

29. Levy O, Netea MG. Innate immune memory: implications for development of pediatric immunomodulatory agents and adjuvanted vaccines. Pediatr Res 2014;75:184-8.

30. Pauleau AL, Rutschman R, Lang R, Pernis A, Watowich SS, Murray PJ. Enhancer-mediated control of macrophage-specific arginase I expression. J Immunol 2004;172:7565-73.

31. Gordon S. Alternative activation of macrophages. Nat Rev Immunol 2003;3:23-35.

32. Ganster RW, Taylor BS, Shao L, Geller DA. Complex regulation of human inducible nitric oxide synthase gene transcription by Stat 1 and NF-kappa B. Proc Natl Acad Sci USA 2001;98:8638-43.

33. Vilas-Boas W, Cerqueira BA, Zanette AM, Reis MG, Barral-Netto M, Goncalves MS. Arginase levels and their association with Th17-related cytokines, soluble adhesion molecules (sICAM-1 and sVCAM-1) and hemolysis markers among steady-state sickle cell anemia patients. Ann Hematol 2010;89:877-82.

34. Das P, Lahiri A, Lahiri A, Chakravortty D. Modulation of the arginase pathway in the context of microbial pathogenesis: a metabolic enzyme moonlighting as an immune modulator. PLoS Pathog 2010;6:e1000899.

35. Dai ZL, Li XL, Xi PB, Zhang J, Wu G, Zhu WY. Regulatory role for L-arginine in the utilization of amino acids by pig small-intestinal bacteria Amino Acids 2012;43:233-44.

36. Morgan XC, Tickle TL, Sokol H, et al. Dysfunction of the intestinal microbiome in inflammatory bowel disease and treatment. Genome Biol 2012;13:R79.

37. Davis JS, Anstey NM. Is plasma arginine concentration decreased in patients with sepsis? A systematic review and meta-analysis. Crit Care Med 2011;39:380-5.

38. Weiss SL, Haymond S, Ralay Ranaivo H, et al. Evaluation of asymmetric dimethylarginine, arginine, and carnitine metabolism in pediatric sepsis. Pediatr Crit Care Med 2012;13:e210-8.

39. Celik IH, Demirel G, Canpolat FE, Dilmen U. Reduced plasma citrulline levels in low birth weight infants with necrotizing enterocolitis. J Clin Lab Anal 2013;27:328-32.

40. Zamora SA, Amin HJ, McMillan DD, et al. Plasma L-arginine concentrations in premature infants with necrotizing enterocolitis. J Pediatr 1997;131:226-32.

41. Becker RM, Wu G, Galanko JA, et al. Reduced serum amino acid concentrations in infants with necrotizing enterocolitis. J Pediatr 2000;137: 785-93.

42. Nair J, Gugino SF, Nielsen LC, et al. Packed red cell transfusions alter mesenteric arterial reactivity and nitric oxide pathway in preterm lambs. Pediatr Res 2013;74:652-7.

43. Chuang CK, Lin SP, Lee HC, et al. Free amino acids in full-term and pre-term human milk and infant formula. J Pediatr Gastroenterol Nutr 2005;40:496-500

\section{Badurdeen et al.}

44. Carratù B. Nitrogenous components of human milk: non-protein nitrogen, true protein and free amino acids. Food Chem 2003;81:357-62.

45. Popovic PJ, Zeh HJ 3rd, Ochoa JB. Arginine and immunity. J Nutr 2007;137(6 Suppl 2):1681S-6S

46. Drover JW, Dhaliwal R, Weitzel L, Wischmeyer PE, Ochoa JB, Heyland DK. Perioperative use of arginine-supplemented diets: a systematic review of the evidence. J Am Coll Surg 2011;212:385-99, 399.e1.

47. Weimann A, Braga M, Harsanyi L, et al.; DGEM (German Society for Nutritional Medicine); ESPEN (European Society for Parenteral and Enteral Nutrition). ESPEN Guidelines on Enteral Nutrition: Surgery including organ transplantation. Clin Nutr 2006;25:224-44.

48. Kalil AC. Is it time to replace L-arginine in severe sepsis? Crit Care Med 2011;39:417-8.

49. Zhou M, Martindale RG. Arginine in the critical care setting. J Nutr 2007;137:1687S-1692S.

50. Galbán C, Montejo JC, Mesejo A, et al. An immune-enhancing enteral diet reduces mortality rate and episodes of bacteremia in septic intensive care unit patients. Crit Care Med 2000;28:643-8.

51. Bertolini G, Iapichino G, Radrizzani D, et al. Early enteral immunonutrition in patients with severe sepsis: results of an interim analysis of a randomized multicentre clinical trial. Intensive Care Med 2003;29:834-40.

52. Kalil AC, Sevransky JE, Myers DE, et al. Preclinical trial of L-arginine monotherapy alone or with $\mathrm{N}$-acetylcysteine in septic shock. Crit Care Med 2006;34:2719-28.

53. Gonce SJ, Peck MD, Alexander JW, Miskell PW. Arginine supplementation and its effect on established peritonitis in guinea pigs. JPEN J Parenter Enteral Nutr 1990;14:237-44.

54. Zaloga GP, Roberts PR, Marik P. Feeding the hemodynamically unstable patient: a critical evaluation of the evidence. Nutr Clin Pract 2003;18: 285-93.

55. Koletzko B, Goulet O, Hunt J, Krohn K, Shamir R. 1. Guidelines on Paediatric Parenteral Nutrition of the European Society of Paediatric Gastroenterology, Hepatology and Nutrition (ESPGHAN) and the European Society for Clinical Nutrition and Metabolism (ESPEN), Supported by the European Society of Paedia. J Pediatr Gastroenterol Nutr 2005;41:Suppl 2:S1-87

56. McIntosh N, Mitchell V. A clinical trial of two parenteral nutrition solutions in neonates. Arch Dis Child 1990;65(7 Spec No):692-9.

57. Oladipo OO, Weindel AL, Saunders AN, Dietzen DJ. Impact of premature birth and critical illness on neonatal range of plasma amino acid concentrations determined by LC-MS/MS. Mol Genet Metab 2011;104:476-9.

58. Rutherfurd-Markwick KJ, Hendriks WH, Morel PC, Thomas DG. The potential for enhancement of immunity in cats by dietary supplementation. Vet Immunol Immunopathol 2013;152:333-40.

59. Ren W, Chen S, Yin J, et al. Dietary arginine supplementation of mice alters the microbial population and activates intestinal innate immunity. J Nutr 2014;144:988-95.

60. Gianotti L, Alexander JW, Pyles T, Fukushima R. Arginine-supplemented diets improve survival in gut-derived sepsis and peritonitis by modulating bacterial clearance. The role of nitric oxide. Ann Surg 1993;217:644-53; discussion 653-4.

61. Chau JY, Tiffany CM, Nimishakavi S, et al. Malaria-associated L-arginine deficiency induces mast cell-associated disruption to intestinal barrier defenses against nontyphoidal Salmonella bacteremia. Infect Immun 2013;81:3515-26.

62. Viana ML, Dos Santos Rd, Generoso Sde V, et al. The role of L-argininenitric oxide pathway in bacterial translocation. Amino Acids 2013;45: 1089-96.

63. Poeze M, Bruins MJ, Kessels F, Luiking YC, Lamers WH, Deutz NE Effects of L-arginine pretreatment on nitric oxide metabolism and hepatosplanchnic perfusion during porcine endotoxemia. Am J Clin Nutr 2011;93:1237-47.

64. Shang HF, Wang YY, Lai YN, Chiu WC, Yeh SL. Effects of arginine supplementation on mucosal immunity in rats with septic peritonitis. Clin Nutr 2004;23:561-9.

65. Wang YY, Shang HF, Lai YN, Yeh SL. Arginine supplementation enhances peritoneal macrophage phagocytic activity in rats with gut-derived sepsis. JPEN J Parenter Enteral Nutr 2003;27:235-40. 


\section{Arginine in preterm newborn immunity}

66. Kul M, Vurucu S, Demirkaya E, et al. Enteral glutamine and/or arginine supplementation have favorable effects on oxidative stress parameters in neonatal rat intestine. J Pediatr Gastroenterol Nutr 2009;49:85-9.

67. Puiman PJ, Stoll B, van Goudoever JB, Burrin DG. Enteral arginine does not increase superior mesenteric arterial blood flow but induces mucosal growth in neonatal pigs. J Nutr 2011;141:63-70.

68. Castro IC, Oliveira BB, Slowikowski JJ, et al. Arginine decreases Cryptosporidium parvum infection in undernourished suckling mice involving nitric oxide synthase and arginase. Nutrition 2012;28:678-85.

69. Tan B, Yin Y, Kong X, et al. L-Arginine stimulates proliferation and prevents endotoxin-induced death of intestinal cells. Amino Acids 2010;38 1227-35.

70. Hackam DJ, Afrazi A, Good M, Sodhi CP. Innate immune signaling in the pathogenesis of necrotizing enterocolitis. Clin Dev Immuno 2013;2013:475415.

71. Yazji I, Sodhi CP, Lee EK, et al. Endothelial TLR4 activation impairs intestinal microcirculatory perfusion in necrotizing enterocolitis via eNOS-NOnitrite signaling. Proc Natl Acad Sci USA 2013;110:9451-6.

72. Amin HJ, Zamora SA, McMillan DD, et al. Arginine supplementation prevents necrotizing enterocolitis in the premature infant. J Pediatr 2002;140:425-31.

73. Polycarpou E, Zachaki S, Tsolia M, et al. Enteral L-arginine supplementation for prevention of necrotizing enterocolitis in very low birth weight neonates: a double-blind randomized pilot study of efficacy and safety. JPEN J Parenter Enteral Nutr 2013;37:617-22.

74. Wu G, Jaeger LA, Bazer FW, Rhoads JM. Arginine deficiency in preterm infants: biochemical mechanisms and nutritional implications. J Nutr Biochem 2004; 15:442-51.

75. Illsinger S, Schmidt KH, Lücke T, Vaske B, Bohnhorst B, Das AM. Plasma and urine amino acid pattern in preterm infants on enteral nutrition: impact of gestational age. Amino Acids 2010;38:959-72.

\section{Integrated Mechanism Review}

76. Bizzarro MJ, Ehrenkranz RA, Gallagher PG. Concurrent bloodstream infections in infants with necrotizing enterocolitis. J Pediatr 2014;164:61-6.

77. Das P, Singh AK, Pal T, Dasgupta S, Ramamurthy T, Basu S. Colonization of the gut with Gram-negative bacilli, its association with neonatal sepsis and its clinical relevance in a developing country. J Med Microbiol 2011;60(Pt 11):1651-60.

78. Costa KA, Soares AD, Wanner SP, et al. L-arginine supplementation prevents increases in intestinal permeability and bacterial translocation in male Swiss mice subjected to physical exercise under environmental heat stress. J Nutr 2014;144:218-23.

79. Lee J, Ryu H, Ferrante RJ, Morris SM Jr, Ratan RR. Translational control of inducible nitric oxide synthase expression by arginine can explain the arginine paradox. Proc Natl Acad Sci USA 2003;100:4843-8.

80. Blachier F, Mignon A, Soubrane O. Polyamines inhibit lipopolysaccharideinduced nitric oxide synthase activity in rat liver cytosol. Nitric Oxide 1997;1:268-72.

(1) (2) This work is licensed under a Creative Commons Attribution-NonCommercial-ShareAlike $\quad 3.0$

Unported License. The images or other third party material in this article are included in the article's Creative Commons license, unless indicated otherwise in the credit line; if the material is not included under the Creative Commons license, users will need to obtain permission from the license holder to reproduce the material. To view a copy of this license, visit http://creativecommons.org/licenses/by-nc-sa/3.0/ 